\title{
Health-related quality of life, developmental milestones, and self- esteem in young adults with bleeding disorders
}

\author{
P. F. Limperg ${ }^{1,2}$ - L. Haverman ${ }^{1,2}$ - H. Maurice-Stam ${ }^{1,2} \cdot$ M. Coppens ${ }^{3}$. \\ C. Valk ${ }^{3}$ M. J. H. A. Kruip ${ }^{4}$ J. Eikenboom ${ }^{5} \cdot$ M. Peters ${ }^{6} \cdot$ M. A. Grootenhuis ${ }^{1,2}$
}

Accepted: 24 August 2017/Published online: 12 September 2017

(c) The Author(s) 2017. This article is an open access publication

\begin{abstract}
Background The treatment of bleeding disorders improved in the last decades. However, the effect of growing up with bleeding disorders on developmental, emotional, and social aspects is understudied. Therefore, this study assesses HRQOL, developmental milestones, and self-esteem in Dutch young adults (YA) with bleeding disorders compared to peers.

Methods Ninety-five YA (18-30 years) with bleeding disorders (78 men; mean 24.7 years, SD 3.5) and 17 women (mean 25.1 years, SD 3.8) participated and completed the Pediatric Quality of Life Inventory Young Adult version, the Course of Life Questionnaire, and the Rosenberg Self-Esteem Scale. Differences between patients with bleeding disorders and their peers, and between hemophilia severity groups, were tested using Mann-Whitney $U$ tests.
\end{abstract}

M. A. Grootenhuis

m.a.grootenhuis@amc.nl

1 Psychosocial Department, Emma Children's Hospital, AMC, Postbox 22660, 1100 DD Amsterdam, The Netherlands

2 Amsterdam Public Health Research Institute, Amsterdam, The Netherlands

3 Department of Vascular Medicine, Hemophilia Comprehensive Care Treatment Center, AMC, Amsterdam, The Netherlands

4 Department of Hematology, Hemophilia Comprehensive Care Treatment Center, Erasmus University Medical Center, Rotterdam, The Netherlands

5 Department of Thrombosis and Hemostasis, Leiden University Medical Center, Leiden, The Netherlands

6 Department of Pediatric-Hematology, Emma Children's Hospital and Hemophilia Comprehensive Care Treatment Center, AMC, Amsterdam, The Netherlands
Results YA men with bleeding disorders report a slightly lower HRQOL on the total scale, physical functioning, and school/work functioning in comparison to healthy peers (small effect sizes). YA men with severe hemophilia report more problems on the physical functioning scale than nonsevere hemophilia. YA men with bleeding disorders achieved more psychosexual developmental milestones than peers, but show a delay in 'paid jobs, during middle and/or high school.' A somewhat lower self-esteem was found in YA men with bleeding disorders in comparison to peers (small effect size). For YA women with bleeding disorders, no differences were found on any of the outcomes in comparison to peers.

Conclusion This study demonstrates some impairments in HRQOL and self-esteem in YA men with bleeding disorders. By monitoring HRQOL, problems can be identified early, especially with regard to their physical and professional/school functioning.

Keywords Hemophilia · Young adults · Health-related quality of life - Developmental milestones · Self-esteem

$\begin{array}{ll}\text { Abbreviations } & \\ \text { HRQOL } & \text { Health-Related Quality of Life } \\ \text { YA } & \text { Young adults } \\ \text { PedsQL_YA } & \begin{array}{l}\text { Pediatric Quality of Life Inventory Young } \\ \text { Adult Version }\end{array} \\ \text { CoLQ } & \text { Course of Life Questionnaire } \\ \text { RSES } & \begin{array}{l}\text { Rosenberg Self-Esteem Scale } \\ \text { DHPSYA }\end{array} \\ & \begin{array}{l}\text { Dutch Hemophilia Patient Society Young } \\ \text { Adult committee }\end{array}\end{array}$

Abbreviations

HRQOL Health-Related Quality of Life

Young adults

PedsQL_YA Pediatric Quality of Life Inventory Young Adult Version

Course of Life Questionnaire

Rosenberg Self-Esteem Scale Adult committee 


\section{Introduction}

The term bleeding disorder refers to a deficiency of the blood clotting system, in which bleeding is prolonged and excessive. Hemophilia A and B and von Willebrand (VWD) are the most common bleeding disorders identified [1]. Hemophilia is X-linked; women are carriers and men are affected. Symptoms of hemophilia are spontaneous and posttraumatic bleeds [2]. Other inherited bleeding disorders, such as VWD, affect men and women. For those, mildly affected patients may suffer from frequent nosebleeds and bruises, while patients with a more severe type may have symptoms similar to those of hemophilia [1]. For women with bleeding disorders, heavy menstruation and postpartum bleeding are common [3].

Mid previous century people with bleeding disorders could only be treated with whole blood or fresh plasma obtained from donors [4]. Most people affected by severe hemophilia died in childhood or in early adulthood $[4,5]$. Since the 1980s, as a result of the hepatitis and human immunodeficiency virus (HIV) crises that occurred in Western Europe and the US due to contaminated blood products, safe plasma concentrates of coagulation factors have been produced, and genetically engineered factors led to the industrial production of factor products $[2,4,6]$. Prophylactic treatment was used in order to prevent bleeding and joint damage, ultimately allowing patients to maintain a near normal lifestyle [7].

Despite the available adequate treatment, patients with bleeding disorders still endure difficulties and impairments in daily life, such as hospital visits, frequent injections, and limited participation in (sport) activities [8]. A vulnerable group of patients with bleeding disorders are adolescents and young adults (YA). Transition into adulthood is a critical phase for all children, but growing up with a bleeding disorder brings additional challenges compared with healthy children; acceptance of the limitations of the bleeding disorder, the shift from parental care to self-care, the move from a pediatric to an adult treatment facility, the search for employment that provides adequate medical insurance, or starting a family $[9,10]$. Adolescents with bleeding disorders usually start with learning self-infusion around the age of eleven, a procedure which involves complex self-management skills [11, 12]. Despite the advantages of being able to provide care at home (e.g., less hospital visits, more independence), the large responsibility for management of the bleeding disorder is burdensome, especially for patients with hemophilia [13, 14].

During childhood, psychosocial care in the Netherlands is extensive for children with bleeding disorders [15], to prepare them for the transition period. Patients are expected to be independent and fully responsible for their own treatment when they are 18 years making the transition to adult healthcare challenging. Research in YA with hemophilia in Canada showed that YA have more joint disease and slightly worse HRQOL with regard to physical functioning and pain than their younger counterparts and healthy peers [16]. On top of that, research has demonstrated that the mean age of YA for complete self-management and responsibility is not reached until they are 22 years [11].

To identify what elements are relevant and impact daily life of YA (ages 18-30 years) with bleeding disorders, we conducted a foregoing qualitative study. Focus groups revealed that, despite growing up in this era and in a developed country with adequate treatment available, YA still do experience obstacles and issues in daily life with regard to their treatment and condition [17]. For example, being autonomous (in relation to parents, travel, sports, professionally), as well as development of self-esteem (illness perception, acceptance, and being able to pursue ambitions as much as healthy peers), were identified as major issues [17].

These qualitative results have led us to conceive the current study, in which we aim to quantify our findings in a larger group of YA with bleeding disorders. By administering validated questionnaires we can capture the themes retrieved from the focus groups, in a larger sample of YA with bleeding disorders. By comparing them to the peers from the general population, we hope to gain insight into the HRQOL, psychosocial development, and self-esteem of YA with bleeding disorders. Furthermore, in this study, we will examine the influence of severity of hemophilia on these outcomes in YA men with hemophilia, as this is the largest group.

\section{Methods}

\section{Participants}

Eligible patients were YA aged 18-30 years with hemophilia A/B [clotting factor $<1 \%$ (severe) or $1-40 \%$ (nonsevere)], VWD, or other congenital bleeding disorders. Patients were treated in one of the three participating treatment centers in the Netherlands (Academic Medical Center Amsterdam, Erasmus University Medical Center Rotterdam and Leiden University Medical Center) or a member of the Dutch Hemophilia Patient Society Young Adult committee (DHPSYA; which includes patients with different congenital bleeding disorders meeting the inclusion criteria). 


\section{Procedure}

After approval by the Medical Ethics Committees of the Academic Medical Centre, invitational letters, including login codes for online questionnaires, were sent out between May and October 2015 to the eligible patients of the medical centers and to members of the DHPSYA. To recruit additional respondents, the DHPSYA emailed their members, and posted an online call for participation on their website and Facebook page. Informed consent was obtained from all participants.

\section{Measures}

\section{Sociodemographics and medical characteristics}

Sociodemographics of the participants were assessed with questions from the Course of Life Questionnaire (CoLQ) [18, 19], regarding age, gender, ethnicity, education, employment, and marital status. Education was divided into three categories according to the classification of Statistics Netherlands; low (primary education, lower vocational education, lower and middle general secondary education), middle (middle vocational education, higher secondary education, pre-university education), high (higher vocational education, university). In addition, the respondents were asked medical questions regarding the type of disease, severity [severe hemophilia: $<1 \%$ clotting factor present in blood, non-severe hemophilia (1-40\% clotting factor)], treatment, and number of bleedings that occurred over the past 6 months that required treatment.

\section{Pediatric Quality of Life Inventory (PedsQL 4.0) generic core scales young adult version}

The Dutch version of the Pediatric Quality of Life Inventory generic core scales young adult version (PedsQL_YA) was used [20, 21]. The PedsQL_YA is a generic self-report HRQOL instrument developed for YA aged 18-30 years and contains 23 items in four scales; physical health (eight items), emotional functioning (five items), social functioning (five items), and work/school functioning (five items). A psychosocial health scale score and a total scale score can be computed. Answers are divided over a 5-point Likert scale, consisting of the options 'never' (0) to 'almost always' (4). Each answer is reversed scored and rescaled to a 0-100 scale. Higher scores on the PedsQL_YA indicate better reported HRQOL. The validity and reliability of the PedsQL scales are good [21]. The internal consistencies (Cronbach's alpha) in our sample ranged from .72 (social functioning) to .90 (total scale). A norm group of 649 YA peers from the Dutch population (18-30 years), healthy and with chronic illnesses, was available [21].
Course of life questionnaire (CoLQ)

The Course of life questionnaire (CoLQ) was used to assess the psychosocial developmental trajectory retrospectively (course of life; CoL) [18, 19]. The CoLQ has 74 items in five scales, concerning behaviors that are characteristic of certain age stages, developmental tasks, and the limitations patients might encounter when growing up with a chronic illness. We used three scales of the CoLQ that covered psychosocial development: development of autonomy (six items, score 6-12), social development (12 items, score 12-24), and psychosexual development (four items, score 6-12). A higher score on the scales indicates the accomplishment of more developmental milestones and therefore a more favorable course of life [19]. The validity and the test-retest reliability of the CoLQ scales are good [18, 19]. The internal consistencies (Cronbach's alpha) in our sample ranged from 0.48 (development of autonomy) to 0.77 (psychosexual development). A recently updated norm group of 655 YA peers from the general Dutch population (18-30 years) was available.

\section{Rosenberg self-esteem scale (RSES)}

The Rosenberg self-esteem scale (RSES) was used to assess self-esteem [22]. The RSES measures the self-acceptance aspect of self-esteem or the overall sense of being capable, worthwhile, and competent. The RSES is a selfadministered questionnaire with 10-items on a 4-point scale, ranging from one (strongly agree) to four (strongly disagree), with possible scores ranging from 10 to 40 [22]. A higher score indicates a higher self-esteem. The internal consistency (Cronbach's alpha) in our sample was 0.80 . A norm group of 1002 YA peers (18-30 years) was available [23].

\section{Data analysis}

The Statistical Package for Social Sciences (SPSS) version 23.0 was used for all statistical analyses [24]. First, preparatory analyses were performed: calculation of internal consistencies (Cronbach's alpha), computing of scale scores, and the distributions of scale scores were considered.

Next, descriptive analyses were performed to describe the sample. Demographic characteristics of our sample and the norm groups or peers were compared (age, gender, ethnicity, education, employment, and marital status) using $\chi^{2}$-tests for categorical data and $t$ tests for continuous data.

Differences on the PedsQL scale scores, CoLQ scales, and RSES between the patients with bleeding disorders and their peers were analyzed with Mann-Whitney $U$ tests. Differences on the scale items of the CoLQ, which 
represent the achievement of the individual milestones, were analyzed with $\chi^{2}$-tests. To adjust for multiple testing, we used a Bonferroni correction for the PedsQL YA (0.05/ $6=0.008)$ and CoLQ scale scores $(0.05 / 3=0.017)$ and as well as for the individual milestones (autonomy: 0.05/ $6=0.008$, social development: $0.05 / 12=0.004$, and psychosexual development: $0.05 / 4=0.013$ ).

Since hemophilia affects primarily men, the sample of YA with bleeding disorders had a significantly higher percentage $(p<0.01,82 \%)$ of men than the peer groups (49\%). In addition, bleeding disorders have a different impact on men and women, and therefore we analyzed the outcomes for gender separately. Since bleeding disorders other than hemophilia have a less clear distinction in severity, differences between YA men with severe and non-severe hemophilia were analyzed only, using MannWhitney $U$ tests.

For the results of the Mann-Whitney $U$ tests, effect sizes $(r)$ were calculated by dividing the Z-scores by the square root of the sample size. Effect sizes up to 0.1, 0.3, and 0.5 were considered to be small, moderate, and large, respectively [25].

\section{Results}

\section{Sociodemographic and medical characteristics}

In total, 95 YA completed the online questionnaires. From the Academic Medical Center Amsterdam 34 YA participated (46\% response rate), from the Erasmus University Medical Center Rotterdam 37 YA participated (46\% response rate), from Leiden University Medical Center 10 YA participated (33\% response rate), from the DHPSYA 10 YA participated ( $83 \%$ response rate), and the online call yielded another 3 YA (response rate unknown). The mean age of the 78 men $(82.1 \%)$ was 24.7 years (SD 3.5) and of the 17 women (17.9\%) 25.1 years (SD 3.8). Table 1 represents the sociodemographic and medical characteristics of the study population. The YA men in our sample were more often not employed in a paid job $(p<0.05)$ than peers in the PedsQL and CoLQ norm populations. Age, educational level, ethnicity, and marital status did not differ from these norm populations. Age did not differ from the RSES norm population.

\section{HRQOL}

YA men with bleeding disorders reported significantly lower HRQOL on the total scale, physical health scale, and school/work functioning scale in comparison to healthy men on the PedsQL_YA, with small effect sizes (see Table 2). There were no differences found between
HRQOL of YA with bleeding disorders and HRQOL of peers with chronic illnesses. YA men with severe hemophilia (median 81.25, mean 78.86, SD 19.39) reported lower physical functioning than men with non-severe hemophilia (median 93.75, mean 93.06, SD 7.21, $p<0.01$, $r=0.45$ ) on the PedsQL_YA. HRQOL scores did not differ on the other PedsQL_YA scales between severity groups (data not shown).

The HRQOL of YA women with bleeding disorders did not differ significantly from their healthy or chronically ill peers.

\section{Developmental milestones}

Regarding YA men with bleeding disorders, no differences were found compared with peers on autonomy development scale level. When looking at the single items (milestones) in the scale, the sample of YA men with bleeding disorders showed a higher score in 'paid chores, elementary school,' but a delay in 'paid jobs, during middle and/or high school.' On the social development scale, no differences were found on a scale level between YA men with bleeding disorders and their peers, nor on item level. YA men with bleeding disorders scored significantly higher than their peers on the psychosexual development scale, indicating that they achieved more milestones (see Table 3). When looking at the single items (milestones) in the scale, the sample of YA men with bleeding disorders reported a higher score on 'first time sexual intercourse $<18$ years' than their peers (see Table 5 in Appendix). With regard to severity of hemophilia in men, no differences were found in the achievement of developmental milestones on the scales or at item level (data not shown).

Regarding YA women with bleeding disorders, no differences were found compared with peers on autonomy development scale level. However, when looking at the single items (milestones) in the scale, the sample of YA women with bleeding disorders showed a delay in 'paid jobs, during middle and/or high school.' No differences were found between YA women with bleeding disorders and their peers on the social development and psychosexual development scales, nor at item level, of the CoLQ (see Table 3 and Appendix Table 6).

\section{Self-esteem}

YA men with bleeding disorders reported significantly lower self-esteem than their peers (Table 4), with a small effect size. No differences were found between hemophilia severity groups (data not shown). Self-esteem of YA women with bleeding disorders did not differ significantly from their peers. 
Table 1 Sociodemographic and medical characteristics of young adults with bleeding disorders

\begin{tabular}{|c|c|c|c|c|c|c|}
\hline & \multicolumn{3}{|l|}{ Men } & \multicolumn{3}{|c|}{ Women } \\
\hline & $N$ & M & SD & $N$ & M & SD \\
\hline Age & 78 & 24.7 & 3.5 & 17 & 25.1 & 3.8 \\
\hline Ethnicity (Dutch) & 69 & $88.5(\%)$ & & 16 & $94.1(\%)$ & \\
\hline \multicolumn{7}{|l|}{ Education $^{\dagger}$} \\
\hline High & 19 & $24.4(\%)$ & & 7 & $41.2(\%)$ & \\
\hline Middle & 43 & $55.1(\%)$ & & 6 & $35.3(\%)$ & \\
\hline Low & 16 & $20.5(\%)$ & & 4 & $23.5(\%)$ & \\
\hline Employment (paid job) & 45 & $57.7(\%)$ & & 12 & $70.6(\%)$ & \\
\hline Marital status (married/living together) & 21 & $26.9(\%)$ & & 6 & $35.3(\%)$ & \\
\hline \multicolumn{7}{|l|}{ Type of bleeding disorder } \\
\hline Hemophilia A & 55 & $70.5(\%)$ & & 1 & $5.9(\%)$ & \\
\hline Hemophilia B & 15 & $19.2(\%)$ & & 0 & $0(\%)$ & \\
\hline Von Willebrand type $2 / 3$ & 6 & $7.7(\%)$ & & 10 & $58.8(\%)$ & \\
\hline Other congenital bleeding disorder & 2 & $2.6(\%)$ & & 6 & $35.3(\%)$ & \\
\hline \multicolumn{7}{|l|}{ Type of treatment bleeding disorder } \\
\hline Prophylaxis & 37 & $47.5(\%)$ & & 1 & $5.9(\%)$ & \\
\hline On demand-in case of bleed & 41 & $52.6(\%)$ & & 16 & $94.1(\%)$ & \\
\hline \multicolumn{7}{|l|}{ Severity of hemophilia } \\
\hline Non-severe $(>1 \%)$ & 36 & $51.4(\%)$ & & 1 & $5.9(\%)$ & \\
\hline \multirow[t]{3}{*}{ Severe $(<1 \%)$} & 34 & $48.6(\%)$ & & 0 & $0(\%)$ & \\
\hline & & \multicolumn{2}{|l|}{ Men } & & \multicolumn{2}{|l|}{ Women } \\
\hline & & Median & Range & & Median & Range \\
\hline \multicolumn{2}{|c|}{ Number of bleeds past 6 months requiring treatment } & 1.00 & $0-20.00$ & & 0 & $0-20.00$ \\
\hline
\end{tabular}

\section{Discussion}

This study demonstrates that YA men with bleeding disorders show slight impairments in total HRQOL, physical functioning, school/work functioning (PedsQL_YA), and self-esteem (RSES), in comparison to their (healthy, sexmatched) peers. No differences were found on the CoLQ scales (autonomy and social development), except for psychosexual development.

The YA (aged 18-30 years) in our patient population have been born just after the hepatitis and HIV crises [2]. The current generation of YA with bleeding disorder is therefore expected to grow up with less problems than previous generations. However, our results show that growing up with a bleeding disorder these days still can have a negative impact on daily life of YA, which is in line with research on YA growing up with a chronic illness [21]. Despite adequate treatment, YA men with bleeding disorders still experience moderately impaired physical functioning compared to their healthy peers, especially those with severe hemophilia. Although bleeds occur less frequent than in previous generations, joint bleeds cause cumulative and irreversible damage to joints, with arthropathy and limited physical functioning as a result when boys grow up to be YA.

The finding that YA men with bleeding disorders are still facing difficulties in daily life underlines the findings from the focus groups [17]. This study covers three of the important themes from the focus groups. In line with the qualitative results, we found difficulties with school/work functioning and self-esteem. However, not all results based on the outcomes of the questionnaires are in concordance with the findings from the focus groups. For example, during the focus groups, autonomy development (e.g., gaining independence from parents) was mentioned as challenging, which was not confirmed in this study.

The current findings regarding school/work functioning is not only in line with our former focus group study, but also with other studies. For example, previous research in 2001 in the Netherlands demonstrated that men with severe hemophilia participated less in full-time work compared with the general population [26]. In addition, on the 


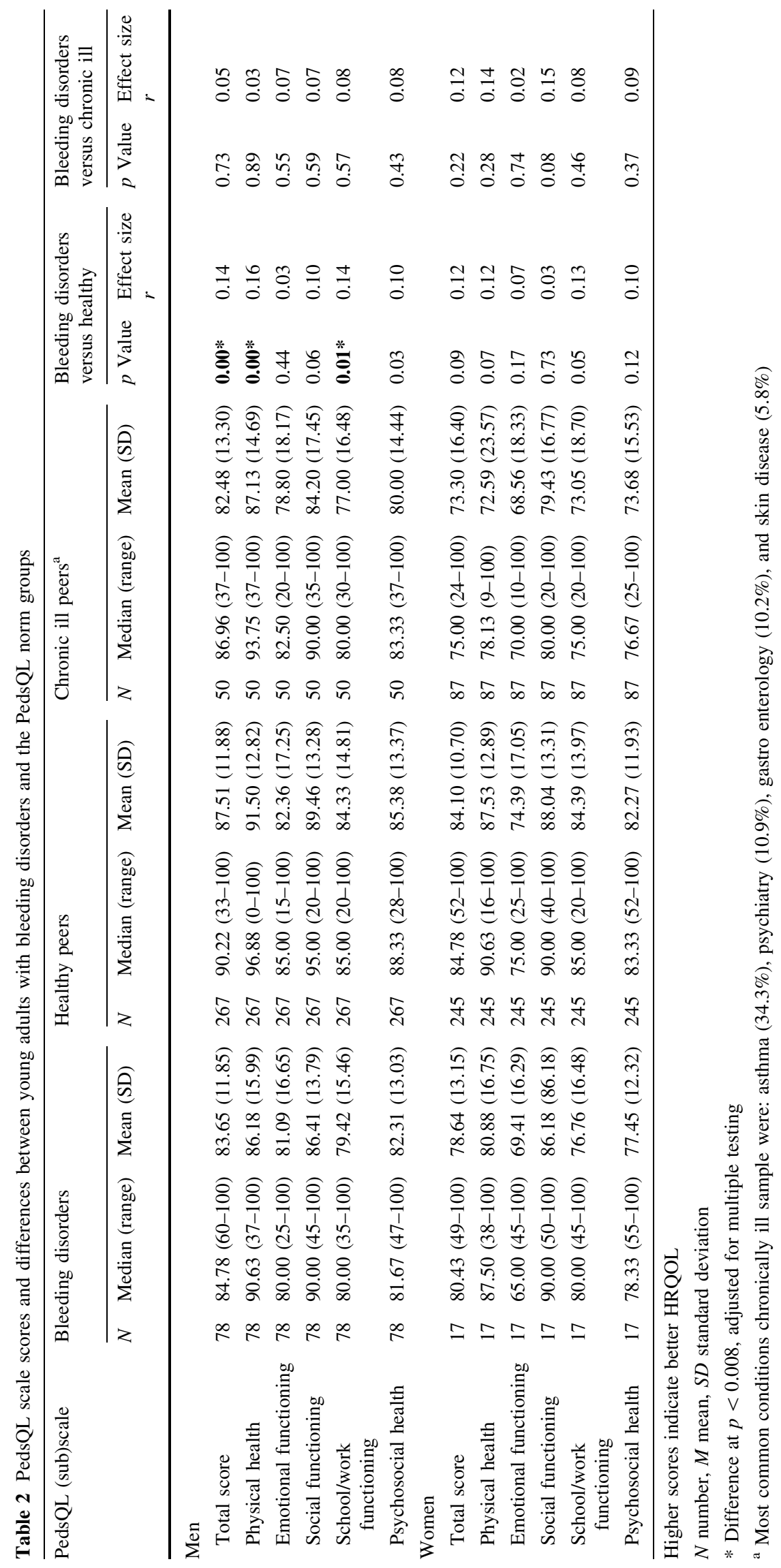


Table 3 CoLQ scale scores and differences between young adults with bleeding disorders and the CoLQ norm group

\begin{tabular}{|c|c|c|c|c|c|c|c|c|}
\hline \multirow[t]{2}{*}{ CoLQ scale } & \multicolumn{3}{|c|}{ Bleeding disorders } & \multicolumn{3}{|c|}{ Norm group } & \multicolumn{2}{|c|}{$\begin{array}{l}\text { Bleeding disorders versus norm } \\
\text { group }\end{array}$} \\
\hline & $N$ & Median (range) & Mean (SD) & $N$ & Median (range) & Mean (SD) & $p$ Value & Effect size $r$ \\
\hline \multicolumn{9}{|l|}{ Men } \\
\hline Autonomy development & 78 & $9.00(6-12)$ & $8.69(1.61)$ & 321 & $9.00(6-12)$ & $8.95(1.44)$ & 0.21 & 0.07 \\
\hline Social development & 78 & $21.00(14-24)$ & $20.42(3.05)$ & 321 & $21.00(12-24)$ & $20.12(2.89)$ & 0.35 & 0.04 \\
\hline Psychosexual development & 78 & $8.00(4-8)$ & $7.14(1.20)$ & 321 & $7.00(4-8)$ & $6.64(1.38)$ & $0.00 *$ & 0.15 \\
\hline \multicolumn{9}{|l|}{ Women } \\
\hline Autonomy development & 17 & $9.00(7-11)$ & $8.82(1.38)$ & 334 & $9.00(6-12)$ & $9.22(1.46)$ & 0.29 & 0.06 \\
\hline Social development & 17 & $22.00(16-24)$ & $20.76(2.59)$ & 334 & $21.00(12-24)$ & $20.33(2.59)$ & 0.51 & 0.04 \\
\hline Psychosexual development & 17 & $7.00(4-8)$ & $6.76(1.39)$ & 334 & $8.00(4-8)$ & $6.94(1.35)$ & 0.57 & 0.03 \\
\hline
\end{tabular}

Higher scores indicate better $\mathrm{CoL}$

$N$ number, $M$ mean, $S D$ standard deviation

* Difference at $p<0.017$, adjusted for multiple testing

Table 4 RSES scores and differences between young adults with bleeding disorders and the RSES norm group

\begin{tabular}{|c|c|c|c|c|c|c|c|c|c|}
\hline & \multirow[t]{2}{*}{ Self-Esteem } & \multicolumn{3}{|c|}{ Bleeding disorders } & \multicolumn{3}{|c|}{ Norm group } & \multicolumn{2}{|c|}{ Bleeding disorders vs norm } \\
\hline & & $N$ & Median (range) & Mean (SD) & $N$ & Median (range) & Mean (SD) & $p$ Value & Effect size $r$ \\
\hline $\operatorname{Men}^{\mathrm{a}}$ & Total scale & 77 & $33.00(18-37)$ & $31.78(4.34)$ & 443 & $33.00(14-40)$ & $33.36(4.32)$ & $0.01 *$ & 0.13 \\
\hline Women & Total scale & 17 & $29.00(22-37)$ & $30.41(3.86)$ & 559 & $31.00(16-40)$ & $31.32(4.65)$ & 0.30 & 0.03 \\
\hline
\end{tabular}

Higher scores indicate higher self-esteem

$N$ number, $M$ mean, $S D$ standard deviation

* Difference at $p<0.05$

${ }^{a}$ One YA man did not complete the RSES

sociodemographic characteristics of our sample, we found a significantly lower rate of paid jobs in YA men with bleeding disorders compared to peers, which has also been found in studies in the US $[27,28]$. Of the YA men in our sample, $50 \%$ indicated they were still in college, while their peers were already working. An explanation could be that YA men with bleeding disorders are more likely to apply for 'white collar' jobs, which are often more suitable jobs for hemophilia patients, since the risk of bleeding due to physical activities in this type of work is lower [26]. In this case, patients with bleeding disorders are more likely to follow full-time education over a longer period of time.

The problems related to school or professional functioning are also interesting in relation to the finding that young adult men with bleeding disorders report a somewhat lower self-esteem than their peers. One can imagine that when a YA feels less successful in a professional sense, or when a YA is not able to pursue professional goals due to physical limitations, this could lead to a decreased self-esteem. Work experience during adolescence, which has shown to be less frequent in adolescents with bleeding disorders, is not only an excellent way to discover skills and interests, but also to experience negative feelings related to limitations of physical capacities [29]. Finding an education or job that fits with some of the physical restrictions that YA with bleeding disorders encounter is important, and guidance and support is desirable, for example, by a social worker or professional coach and strengthen work-related psychosocial skills [30-33]. As an example, Emma at Work, a job mediation agency for YA with chronic diseases at the Academic Medical Center in Amsterdam, can be a useful service [33].

YA men reported to have achieved slightly more psychosexual developmental milestones than their peers ('first time intercourse $<18$ years'). Although this result is in contradiction to our expectations, this finding suggests that YA men growing up with bleeding disorders do not feel limited by their condition, with regard to discovering psychosexual relations during adolescence. However, the CoLQ used in this study measures retrospectively. This does not imply that sexual functioning at present is not hindered by their bleeding disorder or physical impairments, which may have decreased over the years due to bleeds. For example, (fear of) pain, or fear of bleeding during intercourse, may affect sexual functioning. Furthermore, arthropathy in joints may place limitations on sexual functioning, while women 
with bleeding disorders may experience impaired sexuality due to long lasting heavy menstruation $[34,35]$. It would be interesting to explore current sexual functioning more for this population, especially since patients seem to be keen to talk about this subject with their healthcare providers [36]. Psychosexual development and functioning of YA receives very little attention in clinical practice and in literature, and it is important to study this aspect more in depth in the future [35-37].

YA women with bleeding disorders do not show any impairments in HRQOL, psychosocial development on scale level, and self-esteem in comparison to their peers. Only on the autonomy scale of the CoLQ, women with bleeding disorders scored lower on the item 'paid jobs, middle and/or high school.' We assume that because women experience less joint bleeds and consequences from their condition compared to men, this results in less impaired functioning in daily life. Research has shown that women with bleeding disorders are impacted majorly by menstrual disorders compared with their peers, especially during teenage years [38]. Unfortunately, the questionnaires used in this study do not cover questions regarding menorrhagia, which would be interesting to include in the future when studying women with bleeding disorders. Still, we wanted to include this group of young adult women, albeit so small, because research on women with bleeding disorders is scarce. The small sample size causes warranty however in generalization of results.

Some limitations of this study should be taken into account. First, the internal consistency of the autonomy scale was low. However, we looked at individual items on the CoLQ scales to overcome this issue. In addition, these internal consistencies are not exceptional and are in concordance with other studies using the CoLQ [39, 40]. Secondly, we did not have all sociodemographic and medical information of non-respondents. Thirdly, the exact response rate of our study is unknown, due to the fact that we recruited additional participants through on online call. We decided to add this call, because recruitment was quite difficult, possibly due to the time consuming nature of completing the questionnaires. Therefore, we do not know whether the results are representative for YA with bleeding disorders and we could be dealing with an under- or overestimation of the problems of this group YA. Also, effect sizes found in our study are quite small. This should be kept in mind when interpreting and generalizing the results. In addition, it would be interesting to collect longitudinal data during the transitional phase to identify factors that may influence HRQOL and psychosocial adaptation in YA with bleeding disorders, especially because the problems seem to increase from childhood to adulthood [41]. Adding a disease-specific HRQOL questionnaire, which is usually more sensitive for changes over time (e.g., Hemophilia Well-Being Index [42] or HAEMO-
QoL-A [43]), can be valuable in collecting longitudinal HRQOL data $[44,45]$.

In conclusion, this study demonstrates that YA men with bleeding disorders show some impairments in physical functioning, school/work functioning, and self-esteem. Although these YA are functioning quite well, systematic monitoring of HRQOL and psychosocial functioning over time in YA with bleeding disorders in daily clinical practice is important since possible influencing psychosocial factors can change over time. This way, problems can be identified early, especially with regard to their physical and professional/school functioning, in order to optimize their well-being and adaptation to society in the process of transition to adulthood.

Acknowledgements We would like to thank all participating young adults in this study. Also, we are grateful to the Dutch Hemophilia Patient Society for assisting the patient recruitment. We would like to thank Pfizer Pharmaceuticals BV for providing an unrestricted research grant to execute this study.

Funding This study was funded by an unrestricted research grant from Pfizer Pharmaceuticals.

Author's contribution PL carried out the literature study, organized data collection, led data analysis, and drafted the manuscript. LH supervised data collection and data analysis, and critically revised the manuscript. HMS supervised data collection and data analysis, and critically revised the manuscript. $\mathrm{MC}, \mathrm{CV}, \mathrm{MK}$, and JE contributed in organizing data collection and critically revised the manuscript for intellectual content. MP conceived the study, supervised data analysis, and critically revised the manuscript. MG conceived the study, supervised data collection, and critically revised the manuscript for intellectual content. All authors read and approved the final manuscript.

\section{Compliance with ethical standards}

Conflict of interest All authors declare that he/she has no conflict of interest.

Ethical approval All procedures performed in studies involving human participants were in accordance with the ethical standards of the institutional and/or national research committee and with the 1964 Helsinki Declaration and its later amendments or comparable ethical standards.

Informed consent Informed consent was obtained from all individual participants included in the study.

Open Access This article is distributed under the terms of the Creative Commons Attribution 4.0 International License (http://creative commons.org/licenses/by/4.0/), which permits unrestricted use, distribution, and reproduction in any medium, provided you give appropriate credit to the original author(s) and the source, provide a link to the Creative Commons license, and indicate if changes were made.

\section{Appendix}

See Tables 5 and 6. 
Table 5 CoLQ item scores and differences between young adult men with bleeding disorders and the CoLQ norm group

Milestones $\quad \begin{array}{llll}\text { Men with bleeding disorders }(n=78) & & \text { Norm group }(n=321) & N\end{array}$

Autonomy development

Regular chores/tasks in your family, elementary school

Yes

No 47

39.7

$39.7-121$

37.7

0.80

Paid chores, elementary school

Yes
No

33

60.3

200

62.3

Regular chores/tasks in your family, middle and/or high school

Yes

Paid jobs, middle and/or high school

\begin{abstract}
At the age of 18 or younger
\end{abstract}
For the first time vacation without adults

At the age of 17 or younger
At the age of 18 or older/never

Leaving your parents home

Not living with your parents

Social development

At least one year of membership in a sports club/competitive sports, elementary school

Yes
No

$\begin{array}{ll}58 & 74.4 \\ 20 & 25.6\end{array}$

Number of friends in kindergarten through third grade, elementary school

$\begin{array}{lllll}4 \text { or more } & 44 & 56.4 & 194 & 60.4 \\ \text { Less than } 4 & 34 & 43.6 & 127 & 39.6\end{array}$

Number of friends in fourth-sixth grade, elementary school

4 or more
Less than 4

Best friend, elementary school

Yes

Most of the time playing with..., elementary school

Friends
Brothers and/or sisters, parents, on your own

62
16

79.5

At least one year of membership in a sports club/competitive sports, middle and/or high school

$\begin{array}{ll}\text { Yes } & 46 \\ \text { No } & 32\end{array}$

Number of friends, middle and/or high school

4 or more
less than 4

59.0

41.0

Best friend, middle and/or high school

Yes $\quad$ No 26

52
26

66.7

186

57.9

42.1

Belonging to a group of friends, middle and/or high school

Yes

No 
Table 5 continued

\begin{tabular}{|c|c|c|c|c|c|}
\hline \multirow[t]{2}{*}{ Milestones } & \multicolumn{2}{|c|}{ Men with bleeding disorders $(n=78)$} & \multicolumn{2}{|c|}{ Norm group $(n=321)$} & \multirow[t]{2}{*}{$p$} \\
\hline & $N$ & $\%$ & $N$ & $\%$ & \\
\hline \multicolumn{6}{|c|}{ Leisure time, mainly with ..., middle and/or high school } \\
\hline Friends & 65 & 83.3 & 257 & 80.1 & \multirow[t]{2}{*}{0.63} \\
\hline Brothers and/or sisters, parents, on your own & 13 & 16.7 & 64 & 19.9 & \\
\hline \multicolumn{6}{|c|}{ Going out to a bar or disco, middle and/or high school } \\
\hline Sometimes/often & 60 & 76.9 & 236 & 73.5 & \multirow[t]{2}{*}{0.57} \\
\hline Never & 18 & 23.1 & 85 & 26.5 & \\
\hline \multicolumn{6}{|c|}{ At least one year of membership in a sports club/competitive sports, after middle and/or high school } \\
\hline Yes & 39 & 50.0 & 138 & 43.0 & \multirow[t]{2}{*}{0.31} \\
\hline No & 39 & 50.0 & 183 & 57.0 & \\
\hline \multicolumn{6}{|l|}{ Psychosexual development } \\
\hline \multicolumn{6}{|l|}{ First girlfriend/boyfriend } \\
\hline At the age of $\leq 17$ years & 54 & 69.2 & 190 & 59.2 & \multirow[t]{2}{*}{0.12} \\
\hline At the age of $\geq 18$ years & 24 & 30.8 & 131 & 40.8 & \\
\hline \multicolumn{6}{|l|}{ For the first time falling in love } \\
\hline At the age of $\leq 18$ years & 74 & 94.9 & 274 & 85.4 & \multirow[t]{2}{*}{0.02} \\
\hline At the age of $\geq 19$ years & 4 & 5.1 & 47 & 14.6 & \\
\hline \multicolumn{6}{|l|}{ For the first time sexual intimacy } \\
\hline At the age of $\leq 18$ years & 62 & 79.5 & 221 & 68.6 & \multirow[t]{2}{*}{0.07} \\
\hline At the age of $\geq 19$ years & 16 & 20.5 & 100 & 31.2 & \\
\hline \multicolumn{6}{|l|}{ For the first time sexual intercourse } \\
\hline At the age of $\leq 18$ years & 55 & 70.5 & 164 & 51.1 & \multirow[t]{2}{*}{$\mathbf{0 . 0 0} * * *$} \\
\hline At the age of $\geq 19$ years & 23 & 29.5 & 157 & 48.9 & \\
\hline
\end{tabular}

$* p<0.008$ based on $\chi^{2}$ adjusted for multiple testing (autonomy development)

$* * p<0.004$ based on $\chi^{2}$ adjusted for multiple testing (social development)

*** $p<0.013$ based on $\chi^{2}$ adjusted for multiple testing (psychosexual development)

Table 6 CoLQ item scores and differences between YA women with bleeding disorders and the CoLQ norm group

\begin{tabular}{|c|c|c|c|c|c|}
\hline \multirow[t]{2}{*}{ Milestones } & \multicolumn{2}{|c|}{ Women with bleeding disorders $(n=17)$} & \multicolumn{2}{|c|}{ Norm group $(n=334)$} & \multirow[t]{2}{*}{$p$} \\
\hline & $N$ & $\%$ & $N$ & $\%$ & \\
\hline \multicolumn{6}{|l|}{ Autonomy development } \\
\hline \multicolumn{6}{|c|}{ Regular chores/tasks in your family, elementary school } \\
\hline Yes & 6 & 35.3 & 138 & 41.3 & \multirow[t]{2}{*}{0.80} \\
\hline No & 11 & 64.7 & 196 & 58.7 & \\
\hline \multicolumn{6}{|l|}{ Paid chores, elementary school } \\
\hline Yes & 6 & 35.3 & 78 & 23.4 & \multirow[t]{2}{*}{0.25} \\
\hline No & 11 & 64.7 & 256 & 76.6 & \\
\hline \multicolumn{6}{|c|}{ Regular chores/tasks in your family, middle and/or high school } \\
\hline Yes & 8 & 47.1 & 182 & 54.5 & \multirow[t]{2}{*}{0.62} \\
\hline No & 9 & 52.9 & 152 & 45.5 & \\
\hline \multicolumn{6}{|l|}{ Paid jobs, middle and/or high school } \\
\hline At the age of 18 or younger & 9 & 52.9 & 282 & 84.4 & \multirow[t]{2}{*}{$0.00 *$} \\
\hline At the age of 19 or older/never & 8 & 47.1 & 52 & 15.6 & \\
\hline \multicolumn{6}{|c|}{ For the first time vacation without adults } \\
\hline At the age of 17 or younger & 7 & 41.2 & 147 & 44.0 & \multirow[t]{2}{*}{1.00} \\
\hline At the age of 18 or older/never & 10 & 58.8 & 187 & 56.0 & \\
\hline
\end{tabular}


Table 6 continued

\begin{tabular}{|c|c|c|c|c|c|}
\hline \multirow[t]{2}{*}{ Milestones } & \multicolumn{2}{|c|}{ Women with bleeding disorders $(n=17)$} & \multicolumn{2}{|c|}{ Norm group $(n=334)$} & \multirow[t]{2}{*}{$p$} \\
\hline & $N$ & $\%$ & $N$ & $\%$ & \\
\hline \multicolumn{6}{|l|}{ Leaving your parents home } \\
\hline Not living with your parents & 12 & 70.6 & 250 & 74.9 & 0.78 \\
\hline Still living with your parents & 5 & 29.4 & 84 & 25.1 & \\
\hline
\end{tabular}

Social development

At least one year of membership in a sports club/competitive sports, elementary school

$\begin{array}{lrrrr}\text { Yes } & 14 & 82.4 & 266 & 79.6 \\ \text { No } & 3 & 17.6 & 68 & 20.4\end{array}$

Number of friends in kindergarten through third grade, elementary school

$\begin{array}{lrrrr}4 \text { or more } & 13 & 76.5 & 199 & 59.6 \\ \text { Less than } 4 & 4 & 23.5 & 135 & 40.4\end{array}$

Number of friends in fourth-sixth grade, elementary school

$\begin{array}{lrr}4 \text { or more } & 12 & 70.6 \\ \text { Less than } 4 & 5 & 29.4\end{array}$

Best friend, elementary school

Yes

14

82.4

Most of the time playing with....., elementary school
Friends 16
Brothers and/or sisters, parents, on your own 1

At least one year of membership in a sports club/competitive sports, middle and/or high school

Yes

\section{0}

7

94.1

Number of friends, middle and/or high school

$$
\begin{aligned}
& 4 \text { or more } \\
& \text { Less than } 4
\end{aligned}
$$

6

64.7

35.3

Best friend, middle and/or high school

Yes
No

16
1

94.1

Belonging to a group of friends, middle and/or high school

Yes
No

Leisure time, mainly with....., middle and/or high school

Friends 15

Brothers and/or sisters, parents, on your own 2

270.6

Going out to a bar or disco, middle and/or high school

Sometimes/often 9

Never

8

52.9

47.1
11.8

8

At least one year of membership in a sports club/competitive sports, after middle and/or high school

Yes

No

Psychosexual development

First girlfriend/boyfriend

10

41.2

58.8

58.8

41.2
At the age of $\leq 17$ years

At the age of $\geq 18$ years

14

3

10

7

At the age of $\leq 18$ years

At the age of $\geq 19$ years

$14 \quad 82.4$
3

17.6 
Table 6 continued

\begin{tabular}{|c|c|c|c|c|c|}
\hline \multirow[t]{2}{*}{ Milestones } & \multicolumn{2}{|c|}{ Women with bleeding disorders $(n=17)$} & \multicolumn{2}{|c|}{ Norm group $(n=334)$} & \multirow[t]{2}{*}{$p$} \\
\hline & $N$ & $\%$ & $N$ & $\%$ & \\
\hline \multicolumn{6}{|c|}{ For the first time sexual intimacy } \\
\hline At the age of $\leq 18$ years & 15 & 88.2 & 253 & 75.7 & 0.38 \\
\hline At the age of $\geq 19$ years & 2 & 11.8 & 81 & 24.3 & \\
\hline \multicolumn{6}{|c|}{ For the first time sexual intercourse } \\
\hline At the age of $\leq 18$ years & 8 & 47.1 & 212 & 63.5 & 0.20 \\
\hline At the age of $\geq 19$ years & 9 & 52.9 & 122 & 36.5 & \\
\hline
\end{tabular}

$* p<0.008$ based on $\chi^{2}$ adjusted for multiple testing (autonomy development)

$* * p<0.004$ based on $\chi^{2}$ adjusted for multiple testing (social development)

$* * * p<0.013$ based on $\chi^{2}$ adjusted for multiple testing (psychosexual development)

\section{References}

1. Barlow, J. H., Stapley, J., \& Ellard, D. R. (2007). Living with haemophilia and von Willebrand's: a descriptive qualitative study. Patient Education and Counseling, 68(3), 235-242.

2. Mannucci, P. M., \& Tuddenham, E. G. D. (2001). The Hemophilias: from royal genes to gene therapy. New England Journal of Medicine, 344(23), 1773-1779.

3. Khair, K., Holland, M., \& Pollard, D. (2013). The experience of girls and young women with inherited bleeding disorders. Haemophilia, 19(5), e276-e281.

4. Mannucci, P. M. (2008). Back to the future: a recent history of haemophilia treatment. Haemophilia, 14(Suppl 3), 10-18.

5. Franchini, M., \& Mannucci, P. M. (2012). Past, present and future of hemophilia: a narrative review. Orphanet Journal of Rare Diseases, 7, 24.

6. Mannucci, P. M. (2003). Hemophilia: treatment options in the twenty-first century. Journal of Thrombosis and Haemostasis, 1(7), 6.

7. Bauer, K. A. (2015). Current challenges in the management of hemophilia. American Journal of Managed Care, 21, S112-S122.

8. von Mackensen, S. (2007). Quality of life and sports activities in patients with haemophilia. Haemophilia, 13, 38-43.

9. Breakey, V. R., Blanchette, V. S., \& Bolton-Maggs, P. H. (2010). Towards comprehensive care in transition for young people with haemophilia. Haemophilia, 16(6), 848-849.

10. Simmons, G. M., Frick, N., Wang, A., Miller, M. E., \& Fragueiro, D. (2014). Identifying information needs among children and teens living with haemophilia. Haemophilia, 20(1), 1-8.

11. Schrijvers, L., Beijlevelt-Van der Zande, M., Peters, M., Lock, J., Cnossen, M., Schuurmans, M., et al. (2016). Achieving selfmanagement of prophylactic treatment in adolescents: the case of haemophilia. Patient Education and Counseling, 99(7), 1179-1183.

12. Schrijvers, L. H., Beijlevelt-van der Zande, M., Peters, M., Schuurmans, M. J., \& Fischer, K. (2012). Learning intravenous infusion in haemophilia: experience from the Netherlands. Haemophilia, 18(4), 516-520.

13. DeKoven, M., Karkare, S., Kelley, L. A., Cooper, D. L., Pham, H., Powers, J., et al. (2014). Understanding the experience of caring for children with haemophilia: cross-sectional study of caregivers in the United States. Haemophilia, 20(4), 541-549.

14. Limperg, P. F., Haverman, L., Peters, M., \& Grootenhuis, M. A. (2016). Psychosocial functioning of mothers of boys with haemophilia. Haemophilia, 22(1), e57-e60.
15. Limperg, P. F., Haverman, L., Beijlevelt, M., van der Pot, M., Zaal, G., de Boer, W. A., Fijnvandraat, K., Peters, M., \& Grootenhuis, M. A. (2017). Psychosocial care for children with hemophilia and their parents in the Netherlands. Haemophilia, 23(3), 362-369.

16. St-Louis, J., Urajnik, D. J., Ménard, F., Cloutier, S., Klaassen, R. J., Ritchie, B., et al. (2016). Generic and disease-specific quality of life among youth and young men with hemophilia in Canada. BMC Hematology, 16(1), 13.

17. Limperg, P., Peters, M., Gibbons, E., Coppens, M., Valk, C., Grootenhuis, M., et al. (2016). Themes in daily life of adolescents and young adults with congenital bleeding disorders: a qualitative study. Haemophilia, 22(4), e330-e333.

18. Grootenhuis, M. A., Stam, H., Destree-Vonk, A., Heymans, H. S., \& Last, B. F. (2003). Levensloop vragenlijst voor jong-volwassenen. [Course of life questionnaire for young adults]. Gedrag en Gezondheid, 31(1), 336-350.

19. Stam, H., Grootenhuis, M. A., \& Last, B. F. (2005). The course of life of survivors of childhood cancer. Psycho-Oncology, 14(3), 227-238.

20. Varni, J. W., \& Limbers, C. A. (2009). The PedsQL 4.0 Generic Core Scales Young Adult Version: feasibility, reliability and validity in a university student population. Journal of Health Psychology, 14(4), 611-622.

21. Limperg, P. F., Haverman, L., van Oers, H. A., Van Rossum, M. A., Maurice-Stam, H., \& Grootenhuis, M. A. (2014). Health related quality of life in Dutch young adults: psychometric properties of the PedsQL generic core scales young adult version. Health Qual Life Outcomes, 12(1), 9.

22. Rosenberg, M. (1965). Society and the adolescent self-image. Princeton: NJ Princeton University Press.

23. Langeveld, N. E., Grootenhuis, M. A., Voûte, P. A., de Haan, R. J., \& van den Bos, C. (2004). Quality of life, self-esteem and worries in young adult survivors of childhood cancer. PsychoOncology, 13(12), 867-881.

24. SPSS, I. (2011). IBM SPSS Statistics for Windows (Version Version 20.0.). Armonk, NY: IBM Corp.

25. Cohen, J. (1988). Statistical power analysis for the behavioral sciences. Hillsdale: Lawrence Erlbaum Associates.

26. Plug, I., Peters, M., Mauser-Bunschoten, E. P., de Goede-Bolder, A., Heijnen, L., Smit, C., et al. (2008). Social participation of patients with hemophilia in the Netherlands. Blood, 111(4), $1811-1815$.

27. Witkop, M., Guelcher, C., Forsyth, A., Hawk, S., Curtis, R., Kelley, L., et al. (2015). Treatment outcomes, quality of life, and 
impact of hemophilia on young adults (aged 18-30 years) with hemophilia. American Journal of Hematology, 90(Suppl 2), S3S10.

28. Curtis, R., Baker, J., Riske, B., Ullman, M., Niu, X., Norton, K., et al. (2015). Young adults with hemophilia in the US: demographics, comorbidities, and health status. American Journal of Hematology, 90(Suppl 2), S11-S16.

29. duTreil, S. (2014). Physical and psychosocial challenges in adult hemophilia patients with inhibitors. Journal of Blood Medicine, $5,115-122$.

30. Young, G. (2010). Transitioning issues in adolescent to young adult hemophilia patients with inhibitors: an approach for a growing population. Blood Coagulation \& Fibrinolysis, 21, 848-857.

31. Cassis, F. R. M. Y. (2007). Psychosocial care for people with hemophilia. Treatment of Hemophilia, 44, 1-12.

32. Cassis, F. R. M. Y., Querol, F., Iorio, A., \& Forsyth, A. (2012). Psychosocial aspects of haemophilia: a systematic review of methodologies and findings. Haemophilia, 18, 101-114.

33. Brouwer, P., \& Giesen, F. B. (2009). De meerwaarde van Emma at work [The added value of Emma at work]. Hoofddorp: TNO Kwaliteit van Leven.

34. Srivastava, A., Brewer, A. K., Mauser-Bunschoten, E. P., Key, N. S., Kitchen, S., Llinas, A., et al. (2013). Guidelines for the management of hemophilia. Haemophilia, 19(1), e1-e47.

35. Mauser-Bunschoten, E., Gianotten, W., Heinjnen, L., \& De Knecht-Van Eekelen, A. (2014). Sexuality and Bleeding Disorders.

36. Parish, K. L. (2002). Sexuality and haemophilia: connections across the life-span. Haemophilia, 8(3), 353-359.

37. Gianotten, W. L., \& Heijnen, L. (2009). Haemophilia, aging and sexuality. Haemophilia, 15(1), 55-62.
38. Von Mackensen, S. (2011). Quality of life in women with bleeding disorders. Haemophilia, 17, 33-37.

39. van der Sluijs Veer, L., Kempers, M. J., Last, B. F., Vulsma, T., \& Grootenhuis, M. A. (2008). Quality of life, developmental milestones, and self-esteem of young adults with congenital hypothyroidism diagnosed by neonatal screening. Journal of Clinical Endocrinology and Metabolism, 93(7), 2654-2661.

40. Stam, H., Hartman, E. E., Deurloo, J. A., Groothoff, J., \& Grootenhuis, M. A. (2006). Young adult patients with a history of pediatric disease: impact on course of life and transition into adulthood. Journal of Adolescent Health, 39(1), 4-13.

41. Limperg, P.F., Joosten, M.M.H., Fijnvandraat, C.J., Peters, M., Grootenhuis, M.A., \& Haverman, L. (2017). Generic and diseasespecific health related quality of life in children with bleeding disorders in the Netherlands. In preparation.

42. Remor, E. (2013). Development and psychometric testing of the hemophilia well-being index. International Journal of Behavioral Medicine, 20(4), 609-617.

43. Rentz, A., Flood, E., Altisent, C., Bullinger, M., Klamroth, R., Garrido, R. P., et al. (2008). Cross-cultural development and psychometric evaluation of a patient-reported health-related quality of life questionnaire for adults with haemophilia. Haemophilia, 14(5), 9.

44. Haverman, L., Limperg, P. F., Young, N. L., Grootenhuis, M. A., \& Klaassen, R. (2016). Paediatric health-related quality of life: what is it and why should we measure it? Archives of Disease in Childhood. doi:10.1136/archdischild-2015-310068.

45. Limperg, P. F., Terwee, C. B., Young, N. L., Price, V. E., Gouw, S. C., Peters, M., et al. (2017). Health-related quality of life questionnaires in individuals with haemophilia: A systematic review of their measurement properties. Haemophilia, 23(4), 497-510. doi:10.1111/hae.13197. 